\title{
1 Cryptogams signify key transition of bacteria and fungi in Arctic sand
}

\section{2 dune succession}

3 Heli Juottonen ${ }^{1 *}$, Minna Männistö ${ }^{2}$, Marja Tiirola ${ }^{1} \&$ Minna-Maarit Kytöviita ${ }^{1}$

$4 \quad{ }^{1}$ Department of Biological and Environmental Science, University of Jyväskylä, Finland

$5 \quad{ }^{2}$ Natural Resources Institute Finland (Luke), Rovaniemi, Finland

6

7

8

9 *Corresponding author. Heli Juottonen, Department of Biological and Environmental

10 Science, P.O. Box 35, 40014 University of Jyväskylä, Finland.

11 email: heli.juottonen@alumni.helsinki.fi 
12

\section{Summary}

- Primary succession models focus on aboveground vascular plants. However, the prevalence of mosses and lichens, i.e. cryptogams, suggests they play a role in soil successions. Here, we explore whether effects of cryptogams on belowground microbes can facilitate progressive shifts in sand dune succession.

- We linked aboveground vegetation, belowground bacterial and fungal community, and soil chemistry in six successional stages in Arctic inland sand dunes: bare sand, grass, moss, lichen, ericoid heath and mountain birch forest.

- Compared to the bare sand and grass stages, microbial biomass and the proportion of fungi increased in the moss stage, and later stage microbial groups appeared despite the absence of their host plants. The microbial communities of the lichen stage resembled the communities in the vascular plant stages. Bacterial community correlated better with soil chemistry than with vegetation, whereas the correlation of fungi with vegetation increased with vascular vegetation.

- Distinct bacterial and fungal patterns of biomass, richness, and plant-microbe interaction showed that the aboveground vegetation change structured the bacterial and fungal community differently. The nonalignment of aboveground vs. belowground changes suggests that cryptogams can drive succession towards vascular plant dominance through microbially mediated facilitation in eroded Arctic soil.

Keywords: Arctic soil, bacterial community, cryptogam, erosion, fungal community, Polytrichum, primary succession, sand dune 


\section{Introduction}

35

Development of vegetation on bare land and the sequence of vegetative stages that predictably follow each other have been described in several theories of succession (Egler, 1954; Wilson et al., 1992). According to widely accepted views, primary succession is influenced by site abiotic conditions (climate, soil parent material, topography) and biotic factors (plant species pool present, order of arrival, species interactions). Although focusing on plants, most models of terrestrial primary succession overlook bryophyte communities (e.g. Connell and Slatyer, 1977; Baker and Walford, 1995), whereas most reports of primary succession include moss and lichen dominated stages (Chapin et al., 1994; Lichter, 1998; Hodkinson et al., 2003; Jones and Henry, 2003).

Ecosystem succession includes stochastic elements for instance through priority effects and, on the other hand, deterministic influences such as competition and facilitation (Måren et al., 2018). Cryptogams, here mosses and lichens, may have diverse but unexplored competitive and facilitative effects on the development of vascular plant and belowground microbial communities. Firstly, dispersal of cryptogams by spores minimizes dispersal limitation - a feature classically included in models explaining succession of vascular plant communities (Makoto and Wilson, 2019). The rapid arrival of mosses warrants them a priority effect in establishing plant communities. Secondly, although mosses and lichens lack roots and rootmediated effects on microbial communities, they affect soil temperature, moisture, and carbon and nitrogen availability, which may promote or inhibit vascular vegetation (Van der Wal and Brooker, 2004; Gornall et al., 2007; Cornelissen et al., 2007; Gornall et al., 2011). Moss rhizoids and litter provide carbon to the belowground soil (Bowden, 1991), and mosses can release carbon also in drying and wetting cycles (Wilson and Coxon, 1999). Many lichens characteristic of primary succession fix atmospheric nitrogen in specific structures called cephalodia (Vitousek, 1994), whereas moss leaves are a habitat of $\mathrm{N}_{2}$-fixing bacteria (DeLuca et al., 2002; Arróniz-Crespo et al., 2014). Thirdly, mosses and lichens produce unique secondary metabolites that may have adverse effects on vascular plants and beneficial or adverse effects on microbes (Cornelissen et al., 2007; Xie and Lou, 2009). 
64

65

66

67

68

69

70

71

72

73

Despite the fact that microbes are the first colonizers of any barren surface and modify soil chemistry during succession, there are only few models predicting successional trajectories of bacteria and fungi (Jackson, 2003; Fierer et al., 2010 Dini-Andreote et al., 2015; Tripathi et al., 2018; Ortiz-Álvarez et al., 2018). Belowground microbial community shifts in early succession are considered to be driven by soil chemistry, external resources and dispersal of microbes, and in later stages by biotic factors, such as establishment and changes in the vegetation (Brown and Jumpponen, 2014; Jiang et al., 2018). Bacterial versus fungal communities can be expected to show distinct trajectories in primary succession: Bacteria are smaller and believed to disperse easier than fungi, which may lead to more deterministic community assembly for bacteria (Schmidt et al., 2014; Powell et al., 2015) and higher influence of priority effects and stochastic effects for fungi (Brown and Jumpponen, 2014; Schmidt et al., 2014; Jiang et al., 2018). Further, the physiological diversity in bacteria enables some of them to survive as autotrophs in bare oligotrophic soils of early successional stages in the absence of plants fixing carbon (Nemergut et al., 2007; Schmidt et al., 2008; Duc et al., 2009). Fungi in these habitats depend on already fixed carbon and nitrogen from wind-blown, ancient, or microbially fixed sources (Schmidt et al., 2014). The critical shift to an ecosystem based on the biomass production by the resident plants is associated with changes in the microbial community (Bardgett and Walker, 2004; Edwards et al., 2006; Blaalid et al., 2012; Knelman et al., 2012). Along succession, the fungi to bacteria ratio generally increases as soil organic matter increases and $\mathrm{pH}$ decreases (Pennanen et al., 2001; Tscherko et al., 2004; Bardgett and Walker, 2004). These results do not, however, fully predict vegetation development in succession. We suggest that belowground changes associated with cryptogams are a key factor in the ecosystem shift from early to late succession. We link belowground community development with that aboveground and expect the interaction strength to vary and that the community changes do not take place in complete synchrony as is inferred in facilitation models (Brooker et al., 2008).

Ecosystems are declining due to soil erosion and loss of vegetation cover (Montgomery, 2007; Vanwalleghem et al., 2017), and it is critical to identify the key factors promoting shifts between non-vegetated and vegetated stages in succession. Identifying microbial and plant communities that signal for the shift from autotrophic to mainly heterotrophic microbial biomass production can help identify factors that drive the shift back to vascular plant cover, soil stabilization, and a productive ecosystem. One example of areas where vegetation has 
97

98

99

100

101

102

103

104

105

106

107

108

109

110

111

112

113

114

115

116

117

118

119

120

121

122

123

124

125

126

127

128

been lost due to environmental changes and lack of recovery are Arctic inland sand dunes.

The dunes have formed from wind-blown sand after the last ice age (Koster, 1988). Plants colonized the dunes later on, but today large areas lack vascular plant cover. Forest fires, insect outbreaks, and overgrazing may have caused the ecosystem degradation (Seppälä, 1995). In our study site in Northern Finland, wind erosion has carved deflation basins into the dunes. Inside the basin, primary succession vegetation stages have developed, and dune slopes surrounding the basins are covered by mountain birch forest, the climax stage in the present climate. Eroding inland sand dunes provide an excellent opportunity to study primary succession due to the mosaic of closely situated successional stages within deflation basin, including moss- and lichen-dominated areas. In temperate inland dunes, the cryptogam stages have been identified as pioneer vegetation stages of the succession (Sparrius et al., 2012). Previous work comparing the start and end points of the Arctic inland dune succession proposed that bacteria and fungi may show distinct successional patterns (Poosakkannu et al., 2017). The role of the cryptogam stages as part of successional trajectories above- and belowground has not been elucidated, although the prevalence of lichens and mosses suggests they are important.

In this study, we explored whether the belowground and aboveground community changes take place in synchrony in Arctic inland sand dune succession. We hypothesized that, compared to bare soil, the cryptogam-covered stages contain belowground soil microbial community more similar to the stages covered by vascular plants. Such nonalignment of belowground vs. aboveground communities could indicate that the cryptogam stages drive succession towards vascular plant dominance through microbially mediated facilitation. Secondly, we compared the belowground responses of two microbial groups - bacteria and fungi - to successional stages defined by aboveground vegetation. We hypothesized that i) in comparison to fungi, bacteria would be more influenced by cryptogam-associated changes in the soil chemical environment because of their limited saprophytic capacity and potential autotrophy, and ii) as powerful and obligate decomposers, fungal community would respond particularly to the appearance of vascular vegetation and consequently organic matter accumulation. Such a pattern would indicate differences in the way vegetation change and plant-microbe interaction structure bacterial vs. fungal communities along the succession. By linking the aboveground vegetation, the belowground microbial communities, and the 
associated soil chemical environment, we aimed to define the multi-faceted role of cryptogams in Arctic ecosystem succession.

\section{Materials and methods}

\section{Study site and sampling}

134 The study site is located in an inland aeolian (i.e. wind-deposited) dune area in Northern

135 Fennoscandia $\left(68^{\circ} 29^{\prime} 16^{\prime \prime} \mathrm{N}, 24^{\circ} 42^{\prime} 13^{\prime \prime} \mathrm{E}\right)$. The 1981-2000 average annual temperature in

136 the region was $-1.3{ }^{\circ} \mathrm{C}$, with extreme air temperatures between $+30{ }^{\circ} \mathrm{C}$ and $-52{ }^{\circ} \mathrm{C}$ and the

137 average annual precipitation $550 \mathrm{~mm}$ (Pirinen et al., 2012). We defined six successional

138 stages in the dunes based on vegetation (Fig. 1a). Although the soil in all the stages was

139 aeolian sand, in three stages the largest part of the surface was mostly exposed sand (92-100

$140 \%$ sand), while in the other three stages vegetation covered the sand (0-52\% sand). The sand-

141 exposed stages ('sandy stages') were: 1) sand: bare loose sand without plants or visible soil

142 crust, 2) grass: bare loose sand with the grass Deschampsia flexuosa and without visible soil

143 crust, and 3) moss: bare loose sand with the moss Polytrichum piliferum. The stages with

144 extensive vegetation cover ('vegetated stages') were 4) lichen: the main species lichens

145 Stereocaulon spp. and Cladonia spp., and the mosses P. piliferum and Racomitrium

146 ericoides, 5) heath: the dominant species dwarf shrub crowberry Empetrum nigrum with

147 Cladonia spp. and/or Stereocaulon spp., and 6) forest: mountain birch (Betula pubescens

148 subsp. czerepanovii) forest, the main species in study plots the shrubs E. nigrum and

149 Vaccinium vitis-idaea, the moss Pleurozium schreberi, D. flexuosa, and the herb Linnaea

150 borealis. The sand, grass, moss, and lichen stages are located at the bottom or on the inner

151 slopes of the deflation basins and heath at the edge of the basins. The remnant mountain birch

152 forests are located around the basins at the crest of the dune or on the outer slope. Permanent

153 study plots of $1 \times 1 \mathrm{~m}$ were established in 2008 and included each of the six vegetation stages

154 in seven deflation basins. The vegetation in the plots was recorded in detail in 2009 by point

155 frequency method (100 points within $50 \times 50 \mathrm{~cm}$, presence/absence and frequency of

156 species). 
158 We sampled soil in each successional stage in four of the basins in July 2011. To take into account that plants and microbes vary at different spatial scales, the soil samples were collected in triplicate. The samples were taken from the depth of $0-10 \mathrm{~cm}$ with a $12.5 \mathrm{~cm} \times$ $12.5 \mathrm{~cm}$ soil corer (72 samples in total: six successional stages $\times$ four basins $\times$ three soil cores per $1 \times 1 \mathrm{~m}$ study plot). Soil was sieved with a $4-\mathrm{mm}$ sieve and frozen at $-20^{\circ} \mathrm{C}$.

\section{Soil chemistry and temperature}

165 Total $\mathrm{C}$ and $\mathrm{N}$ of soil organic matter, soil $\mathrm{P}, \mathrm{Ca}, \mathrm{K}, \mathrm{Na}, \mathrm{Fe}, \mathrm{Mn}, \mathrm{Al}$, and $\mathrm{Mg}$ contents, and $\mathrm{pH}$ 166 were measured as detailed in Methods S1. Soil temperature at the $10 \mathrm{~cm}$ depth was recorded 167 every two hours with Hobo Temp External H08-002-02 loggers coupled with TMC6-HD soil temperature sensor during 2009-2015. We defined maximum temperature as the average temperature of the warmest month (July) and the minimum temperature as the average of the two coldest months (January and February).

\section{Phospholipid fatty acid (PLFA) analysis}

173 Phospholipid fatty acids were extracted as described previously (Francini et al., 2014) from

174 freeze-dried soil (15 $\mathrm{g}$ for sand and grass stages, $10 \mathrm{~g}$ for moss, $8 \mathrm{~g}$ for lichen, $5 \mathrm{~g}$ for heath

175 and $3 \mathrm{~g}$ for forest stage corresponding to OM content). Briefly, lipids were extracted with

176 chloroform:methanol:citrate buffer (Bligh and Dyer, 1:2:0.8 v/v/v), fractionated using silica

177 columns (Bond Elut LRC, Varian), and phospholipids were methylated with mild alkaline

178 methanolysis. The resulting fatty acid methyl esters were analyzed by gas chromatography

179 and PLFAs identified based on a bacterial fatty acid standard mixture (Supelco, Bellefonte,

180 PA, USA) and fatty acids from reference strains. For community analysis, data was expressed

181 as peak area percentage of a single PLFA of the total area of the profile, and for biomass

182 analysis as nmol of PLFAs per gram dry weight ( $\mathrm{gdw}$ ) of soil or per gram OM. The sum of

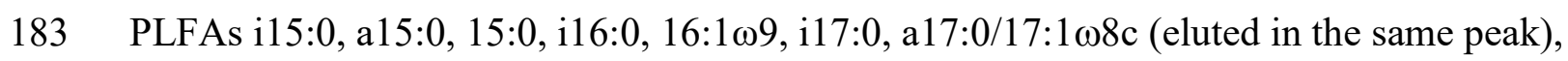

$18417: 0$, cyclo-17:0, 18:1 $\omega 7 \mathrm{c} / \omega 9 \mathrm{t}$ (eluted in the same peak) and cyclo-19:0 were used to

185 represent bacterial biomass and PLFA 18:2 $\omega 6$ fungal biomass. Sum of all these PLFAs was

186 used to represent total microbial biomass. Biomass of selected bacterial groups was 
calculated by multiplying the total microbial biomass of a sample with the relative abundance of the bacterial group in the sample based on 16S rRNA gene sequencing.

\section{DNA extraction and PCR}

DNA was extracted from $0.85 \mathrm{~g}(0.4 \mathrm{~g}$ for forest stage $)$ soil with Powersoil DNA extraction kit (MoBio). Bead beating was carried out with a FastPrep instrument at $5.0 \mathrm{~m} \mathrm{~s}^{-1}$ for $40 \mathrm{~s}$. DNA concentration was determined with Qubit fluorometer and Qubit dsDNA HS kit

194 (Invitrogen).

196 Bacterial and fungal PCRs were carried out as two-step PCR where the second step

197 introduced barcodes and adapters for Ion Torrent sequencing. The first step of bacterial 16S rRNA gene PCR (V1-V2 region) was carried out with primers 27F (5'AGAGTTTGATCCTGGCTCAG-3') and 338R (5'-TGCTGCCTCCCGTAGGAGT-3').The first step of intergenic transcribed region (ITS) PCR for fungi was carried out with primers fITS 7 (5'-GTGARTCATCGAATCTTTG-3') and ITS4 (5'-TCCTCCGCTTATTGATATGC3') (Ihrmark et al., 2012), where the fITS7 primer contained an M13 adapter for the second step (Mäki et al., 2016).

The second step primers introduced barcodes and Ion Torrent adapters A and P1. For bacterial 2nd step PCR, the forward primer was adapter A-barcode-27F, and the reverse primer adapter P1-338R. For the fungal 2nd step PCR, the forward primer was adapter A-

208 barcode-M13 adapter and the reverse primer adapter P1-ITS4. Details for PCR are given in

209 Methods S1. After the second PCR, the duplicate products were pooled, purified with

210 Agencourt AMPure XP purification system (Beckman Coulter), and quantified with Qubit

211 fluorometer and Qubit dsDNA HS kit. Equimolar amounts (10 ng) of products were pooled

212 for sequencing. 
215 Pooled bacterial and fungal PCR products were sequenced after emulsion PCR with the Ion

216 OneTouch system and Ion OT2 400 kit (Life Technologies) on Ion 314 chips with Ion PGM

217 Sequencing $400 \mathrm{Kit}$ (Life Technologies) according to the manufacturer's instructions. The

218 sequences were processed in mothur software package v. 1.38 (Schloss et al., 2009)

219 following the relevant parts of MiSeq SOP protocol (https://mothur.org/wiki/MiSeq_SOP;

220 accessed in January 2017; Kozich et al., 2013). Sequences were quality-filtered using average

221 quality of 25 and a window size of 50 bases, a minimum sequence length of $200 \mathrm{bp}$, a

222 maximum length of $400 \mathrm{bp}$ for bacteria and $410 \mathrm{bp}$ for fungi, and further settings maximum

223 homopolymer length maxhomop=6, maximum number of ambigious bases maxambig $=0$,

224 maximum number of differences to primer sequence pdiffs $=1$, and maximum number of

225 differences to barcode sequence bdiffs $=0$. Bacterial sequences were aligned against Silva

226 database v. 1.23 (Quast et al., 2013). Chimeras were detected with Uchime in de novo mode

227 (Edgar et al., 2011) in mothur. Fungal ITS2 region was extracted and non-fungal sequences

228 were removed with ITSx (Bengtsson-Palme et al., 2013). After quality filtering, alignment

229 for bacteria, and removal of chimeras and non-target sequences, we had 121711 bacterial

230 sequence reads and 279885 fungal reads. Reads were preclustered with setting diffs $=2$

231 (bacteria) or diffs=1 (fungi). The sequences were clustered into 97\% operational taxonomic

232 units (OTUs) using the average neighbor method for bacteria, and the vsearch algorithm for

233 fungi, yielding 5242 bacterial and 1742 fungal OTUs after removal of singletons. Bacterial

234 OTUs were classified against the Silva v. 1.23 database and fungi against the Unite database

235 (Kõljalg et al., 2013). Data was subsampled to the read number of the sample with the lowest

236 number of reads, which was 1055 reads for bacteria and 1605 reads for fungi. Shannon

237 diversity index and coverage were calculated in mothur. Coverage was $76 \pm 6 \%$ for bacteria

238 and $97 \pm 1 \%$ for fungi. The sequence data were submitted to NCBI under BioProject

239 accession PRJNA471306.

241 Statistical analyses

242 Chemistry and microbial biomass were compared among the successional stages using linear

243 mixed models with $\mathrm{R}$ package nlme and function lme with successional stage as a fixed

244 factor and deflation basin as a random blocking factor. Chemistry and biomass values except

$245 \mathrm{pH}$ and $\mathrm{Al}$ were log transformed to normalize their distribution. 
Bacterial and fungal sequence data were converted to relative abundances of OTUs and square root transformed to achieve Hellinger transformation that reduces the weight of OTUs with low counts and zeros. Only OTUs with $5 \geq$ reads were included. Variation of community structure was visualized as non-metric multidimensional scaling (NMDS) plots with function metaMDS using the Bray-Curtis distance measure. Dispersion was visualized in the NMDS plots as ellipses based on standard deviation of sample scores using the ordiellipse function. Multivariate dispersion between the successional stages was tested with betadisper (Bray-Curtis distances). Permutational analysis of variance (PERMANOVA, Anderson, 2001; McArdle and Anderson, 2001) with the adonis2 function (Bray-Curtis distances) was used to compare community structure between the successional stages and in response to environmental variables. In the univariate model for successional stage, the stage was nested within deflation basin. The multivariate PERMANOVA model for environmental variables included $\mathrm{OM}-\mathrm{pH}$ gradient and in addition $\mathrm{Al}$ and minimum soil temperature, which did not correlate with $\mathrm{OM}$ and $\mathrm{pH}$ (Pearson $|\mathrm{r}|<0.7$ ) but differed with successional stage. The OM-pH gradient was defined with detrended correspondence analysis, and the first axis scores were used as a variable in PERMANOVA. Impact of the individual environmental variables was determined with marginal tests. Transitions between successional stages were quantified by calculating average distances of the successional stages from bare sand for bacterial and fungal community structure (Bray-Curtis distances), vegetation (Bray-Curtis distances of square root transformed data) and soil chemistry (Euclidean distances). Using the same distance measures, we carried out Procrustes analysis with the function procrustes to correlate microbial community structure with vegetation, and microbial community structure with soil chemistry (Lisboa et al., 2014). The analysis was based on the first four axes of NMDS analysis of bacterial community, fungal community, vegetation and soil chemistry (stress for all ordinations $\leq 0.07$ ). The strength and the significance of the Procrustes correlation was tested with the function protest (Peres-Neto and Jackson, 2001). Residuals from the Procrustes analysis were used to compare the strength of the plant-microbe and soil chemistry-microbe correlation along the succession by comparing the successional stages with linear mixed models as above for soil chemistry. To separate the effects of vegetation and soil chemistry on the microbial community, we carried out partial Procrustes analysis where the variation due to soil chemistry was first partitioned out by multiple regression of vegetation and microbial data against soil chemistry, and the residuals were then used in Procrustes analysis (Peres-Neto and Jackson, 2001; Lisboa et al., 2014). All multivariate 
analyses were carried out with the vegan package (v.2.4.2, Oksanen et al., 2017) in R.

Significance tests were based on 999 permutations.

283 We identified bacterial and fungal OTUs characteristic to specific successional stages or combinations of stages by indicator species analysis with the package indicspecies using the function multipatt and the association index IndVal.g which corrects for unequal site numbers (De Cáceres and Legendre, 2009). Only OTUs that occurred in the subsampled data at least 12 times, i.e., once in each sample of a successional stage, were included in the analyses. The combinations of stages included in the analyses were each successional stage on its own, all six stages together, all stages except sand, all stages except forest, all stages except sand and grass, all stages except heath and forest, sand+grass, moss+lichen, moss+grass, lichen+heath, heath+forest, sand+grass+moss, moss+lichen+heath, and lichen+heath+forest. Instead of using all possible combinations, we selected the combinations to limit the number of tests and to focus on the combinations most relevant for the aims of the study. OTUs were considered indicator OTUs if their indicator value was $>0.3$ and $p<0.05$. Significance was evaluated with a permutation test (999 permutations). P values were adjusted for multiple comparisons with function p.adjust (method "fdr"). Generalist OTUs present in all successional stages were defined at indicator values $>0.5$, because no $p$ values are generated for taxa present in all sites. The identified indicator OTUs were grouped based on their taxonomic classification at order (bacteria) or class (fungi) level. Unclassified OTUs were included in these comparisons by re-clustering all reads assigned to unclassified bacteria or fungi in mothur at $75 \%$ sequence similarity to represent phylum level similarity for bacteria and class level similarity for fungi (Tedersoo et al., 2014).

To evaluate responses of bacterial and fungal indicator taxa to environmental variables, we used relative abundances of indicator OTUs grouped at order level (bacteria) and class level (fungi), including those unclassified $75 \%$ similarity groups that represented $>0.4 \%$ of all unclassified OTUs. The tested environmental variables were those that best explained microbial community variation $(\mathrm{OM}, \mathrm{pH}, \mathrm{Al}$ for bacteria; $\mathrm{OM}, \mathrm{pH}$, minimum temperature for

309 fungi). The analysis was carried out with the function traitglm in the package mvabund (v.

310 3.13.1, Wang et al., 2012). The function fits fourth corner models to relate sites and their

311 traits to species and species traits. When used without species trait data, it becomes a 
312 predictive model of responses of different OTUs to variation of environmental factors

313 (Brown et al., 2014). The method used was glm1path, fitting a generalized linear model with

314 LASSO penalty, which means that fourth corner coefficients of OTUs not decreasing

315 Bayesian information criterion (BIC) are forced to 0, i.e. no response to environmental

316 variation, to simplify the model (Brown et al., 2014).

317 All statistical analyses were carried out in R v.3.2.5. or v.3.4.0 (RCoreTeam, 2018).

319 Results

320 Soil chemistry and microbial biomass along Arctic sand dune succession

321 The increasing aboveground vegetation cover from bare sand to mountain birch forest was

322 mirrored belowground in increasing soil OM content and decreasing pH (Fig. 1; Pearson

323 correlation $\mathrm{r}=-0.78, \mathrm{p}<0.001$ ). Organic matter content was low in the sand, grass, and moss

324 stage soils $(0.4 \pm 0.2 \%$, mean $\pm \mathrm{SD})$ but increased to $0.9 \pm 0.3 \%$ in the lichen stage and up to

$3254.5 \% \pm 1.7 \%$ in the forest stage (Fig. 1b, Table S1). pH was highest in the grass stage (5.8 \pm $3260.2)$ and lowest in the forest stage $(4.7 \pm 0.1)$ (Fig. 1c). Soil contents of N, P, K, Ca, Mg, Fe and $\mathrm{S}$ increased with increasing OM (Table S1).

Microbial biomass measured as PLFAs per soil dry weight followed closely the OM-pH gradient (Fig. 1e, Fig. S1). The moss stage had similar OM content as bare sand, but its microbial biomass was higher than in the other sandy stages. When related to soil OM, microbial biomass in the moss stage reached a level similar to the lichen and vascular plant stages (Fig. 1d). Similarly, a shift to a higher proportion of fungal to bacterial biomass occurred in the moss stage and was maintained during the later successional stages (Fig. 1f). Overall, the proportion of fungi was highest in the heath stage.

338 Bacterial and fungal community structure based on sequencing (Fig. 2) and PLFA (Fig. S2)

339 followed the order of the vegetation stages on the OM-pH gradient and differed with

340 successional stage (PERMANOVA bacteria $\mathrm{r}^{2}=0.58 \mathrm{P}<0.001$, fungi $\mathrm{r}^{2}=0.59 \mathrm{p}<0.001$ ). The 
341

342

343

344

345

346

347

348

349

350

351

352

353

354

355

356

357

358

359

360

361

362

363

364

365

366

367

368

369

370

371

moss stage grouped with the other sandy stages (sand, grass) with partly overlapping communities, whereas the lichen stage grouped with the vascular plant stages (heath, forest) (Fig. 2a, 2c). It should be noted that multivariate dispersion also differed between the successional stages (betadisper $\mathrm{p}=0.007$ bacteria, $\mathrm{p}=0.001$ fungi). The highest bacterial OTU richness (Fig. 1g) and Shannon diversity (Table S1) were detected in the heath stage, whereas fungal richness and diversity were highest though very variable in bare sand (Fig. 1g, Table S1). The soil parameter that best explained the community variation of bacteria and fungi was the OM-pH gradient, especially in the vegetated stages (Table S2).

To compare successional shifts in bacteria, fungi, vegetation, and soil chemistry, we calculated distance measures from bare sand to the other successional stages (Fig. 3). The largest shift in bacterial and fungal community structure was detected from moss to lichen stage (Fig. 3). Soil chemistry changed most markedly from heath to forest. Vegetation showed increasingly larger shifts in later succession, with the largest shift from heath to forest (Fig. 3). To determine if the microbial communities correlated with vegetation and soil chemistry, we carried out Procrustes analysis (Fig. S3). The bacterial community correlated better with soil chemistry than vegetation (bacteria-vegetation $r=0.71$, bacteria-soil chemistry $\mathrm{r}=0.80, \mathrm{p}=0.001$ for both). The fungal community correlated tighter with vegetation than with soil chemistry (fungi-vegetation $r=0.77$, fungi-soil chemistry $r=0.71, p=0.001$ for both).

When the variation due to soil chemistry was partitioned out, correlation with vegetation remained with lower correlation coefficients (bacteria-vegetation $r=0.51$, fungi-vegetation $\mathrm{r}=0.52$, both $\mathrm{p}=0.001$ ). We then used the Procrustes residuals to compare the strength of the relationship between the plant and microbial community along the succession. The strength of the vegetation-bacteria correlation did not vary with successional stage (Fig. 4). In contrast, vegetation determined fungal community composition more strongly in the heath stage than in the other stages (Fig. 4)

\section{Bacterial taxonomic distribution with succession}

Overall, the most abundant bacterial phyla or classes were Alphaproteobacteria, Actinobacteria, and Acidobacteria (Fig. 2b, Fig. S4). The most abundant bacterial OTU belonged to the candidate phylum WD272 (WPS-2). This phylum was the fourth or fifth most 
372

373

374

375

376

377

378

379

380

381

382

383

384

385

386

387

388

389

390

391

392

393

394

395

396

397

398

399

400

401

402

403

abundant phylum in the sandy and lichen stages (on average 4.6-8.1\%), decreasing in the heath (3.5\%) and forest (0.9\%) (Fig. 2b, Fig. S4). When related to microbial biomass, the abundance of WD272 increased in the moss stage (Fig. S5). WD272 showed abundant indicator OTUs for the sandy stages but also less abundant forest-specific indicators (Fig. 5). Most indicator groups specific for the sandy stages were strongly associated with low OM content (Cytophagales, Deinococcales, Acidobacteria subgroup 4, Pseudonocardiales (Actinobacteria), Oligoflexales (Deltaproteobacteria), unclassified group 9) (Fig. 5). Cyanobacteria, three Chloroflexi groups and unclassified group 2 were indicators for the moss and lichen stages and associated with both low $\mathrm{OM}$ and low $\mathrm{pH}$. Another sign that the moss stage was a key transition stage for bacterial community was that it showed unclassified clusters typical to both sandy and vegetated stages (Fig. S6a). Most indicator groups for the forest stage were indicators also for the other vegetated stages. For example, Acidobacteria subgroup 2 associated with low $\mathrm{pH}$ and subgroup 6 associated with high OM appeared in the moss and lichen stages and had indicators also in the heath and forest stages (Fig. 6). The overall abundance of Acidobacteria increased with decreasing $\mathrm{pH}$ (Pearson correlation $\mathrm{r}=$ $0.81, \mathrm{p}<0.001)$.

\section{Fungal taxonomic distribution with succession}

The fungi at class level were dominated by Ascomycetes, followed by Basidiomycetes, unclassified fungi, and smaller shares of Zygomycota, Rozellomycota, Chytridiomycota, and Glomeromycota (Fig. 2d, Fig. S7). The most abundant Ascomycota class was Leotiomycetes, followed by unclassified ascomycetes and Dothideomycetes. Bare sand had the highest relative abundance of unclassified fungi up to 35\% (Fig. 2d, Fig. S7), and several unclassified clusters were specific to the sandy stages (Fig. S6b) and associated with high pH or low OM (Fig. 6). Other strong indicators of sandy stages included Helotiales and Thelebolales (Leotiomycetes), and Polysporales and Boletales (Agaricomycetes). Lecanoromycetes, containing lichenized fungi, was most abundant in the moss stage (Fig. 2d). Similarly to bacteria, the fungal groups that were the best indicators of the moss and lichen stages were associated with low $\mathrm{OM}$ and low $\mathrm{pH}$ or both, including Lecanoromycetes (Lecanorales, Agyriales, Ostropomycetidae), Agaricomycetes (Cantharellales, Atheliales, Agaricales), and Dothideomycetes (Pleosporales, Capnodiales) (Fig. 6). The most abundant fungal OTU overall and one of the fungal generalists (Table S3) was classified as Pezoloma ericae 
404 (Leotiomycetes; also known as Rhizoscyphus ericae). This OTU was particularly dominant in 405 the heath $(34 \pm 5 \%$ of reads). Its relative abundance was lowest in bare sand $(2 \pm 1 \%)$ and the 406 grass stage $(12 \pm 14 \%)$, but in the moss and lichen stages it increased to $26 \pm 16 \%$. In the forest,

407 its relative abundance was lower than in the cryptogam-dominated stages $(17 \pm 14 \%)$.

\section{Discussion}

410 We hypothesized that the belowground and aboveground succession in Arctic sand dunes are

411 not completely synchronous. Specifically, we hypothesized that the cryptogam-dominated

412 stages of an Arctic sand dune succession involve key belowground components that facilitate

413 transitions towards vascular vegetation. Supporting this hypothesis, the bacterial and fungal

414 communities in the lichen stage soil resembled the communities in the later, vascular plant

415 dominated stages. In the other cryptogam stage studied - the moss stage - the overall

416 microbial communities overlapped with the earlier, sandy stages. Nevertheless, indicative of

417 belowground transitions preceding aboveground succession, microbial biomass per OM and

418 the proportion of fungi increased in the moss stage, and later stage microbial groups appeared

419 despite the absence of their presumed host plants. The higher correlation of bacterial

420 community with soil chemistry than with vegetation and the increase in the strength of plant-

421 fungal interaction with vascular vegetation supported the hypothesis on the different

422 influences of vegetation succession on bacteria and fungi.

424 The dune sand is a harsh habitat with low carbon and nitrogen availability. The initial 425 microbial colonizers must be able to tolerate the oligotrophic conditions either by using the 426 low levels of allocthonous organic matter (Hodkinson et al., 2002) or as autotrophs

427 (Nemergut et al., 2007; Fierer et al., 2010). Comparison of biomass per OM with biomass per 428 soil dry weight shows that the microbial biomass increased in the moss stage when OM 429 potentially available for heterotrophs still remained low. A characteristic group for the early 430 stages from bare sand to lichen was candidate phylum WD272, currently known as WPS-2 431 and recently named Candidatus Eremiobacterota, 'desert bacterial phylum', which are 432 proposed to be autotrophs able to use atmospheric $\mathrm{H}_{2}$ and carbon monoxide (CO) as energy 433 sources (Ji et al., 2017; Holland-Moritz et al., 2018). Another potential $\mathrm{H}_{2}$ - and CO434 oxidizing group in the moss and lichen stages were members of Chloroflexi classified as 
435 Ktedonobacteria (King and King, 2014; Islam et al., 2019). The increased occurrence of

436 WD272 and Chloroflexi in the moss and lichen stages suggests that they may form a basis of

437 biomass accumulation in the Arctic sand dune succession. These microbes may therefore

438 facilitate development of cryptogam cover and heterotrophic microbial community (Connell

439 and Slatyer, 1977; Brooker et al., 2008).

441 Many moss stage microbial groups that were rare or absent in the earlier sandy stages are

442 linked to biological soil crusts. Biocrusts are consortia of microbes, mosses, and lichens that

443 are recognized as the major stabilizing factor in early successional soils worldwide (Weber $e t$

444 al., 2016). The rhizoids of Polytrichum mosses themselves stabilize soil, facilitate $\mathrm{N}_{2}$

445 fixation, and provide OM to the soil (Bowden, 1991). The moss stage showed the highest

446 proportion of Cyanobacteria, known as $\mathrm{N}_{2}$-fixing early colonizers and components of

447 biocrusts. Another distinctive indicator for the cryptogam stages were Chloroflexi, which in

448 dryland and grassland ecosystems occur in moss and lichen biocrusts and in sub-crust soil

449 (Kuske et al., 2012; Navarro-Noya et al., 2014; Maier et al., 2018). In a temperate inland

450 dune succession, a thick $P$. piliferum cover increased microbial biomass compared to bare

451 sand (Sparrius and Kooijman, 2013). In our ecosystem, P. piliferum biomass was small in the

452 moss stage but nonetheless affected the microbial biomass and communities. Therefore $P$.

453 piliferum appeared to have a disproportionate effect on the ecosystem level, suggesting it is a

454 keystone plant species in Arctic sand dunes. The mechanism could be soil stabilization by

455 rhizoids and moss-associated, soil crust-forming microbes. Traditionally, grasses are credited

456 with the initial physical stabilization of sand in dune succession (e.g. Olson, 1958; Ellenberg,

457 2009). Inspecting the soil microbial community structure, it seems that in these Arctic dunes

458 the grass Deschampsia flexuosa may not drive ecosystem succession. Based on our results,

459 we propose that $P$. piliferum could participate in the physical stabilization of Arctic inland

460 dunes and direct succession towards vascular vegetation. Verifying this proposition requires

461 further studies on P. piliferum with emphasis on the role of rhizoids.

Indicative of nonaligned belowground vs. aboveground succession, lichen-forming fungi

464 (Lecanoromycetes, Ascomycetes) were detected in the moss stage soil before the succession 465 stage where they formed lichens. Furthermore, the relative abundance of the dominant fungal

466 OTU Pezoloma ericae increased in the moss stage to levels similar to those in the later 
467

468

469

470

471

472

473

474

475

476

477

478

479

480

481

482

483

484

485

486

487

488

489

490

491

492

493

494

495

496

497

498

stages. We interpret this increase as a possible sign of fungal community shift at the moss stage towards a status where vascular plant establishment is possible. Pezoloma ericae forms mycorrhiza with ericoid plants such as the dominant heath species Empetrum nigrum (Read, 1991; Smith and Read, 2008). However, no known host plants of P. ericae were detected in the moss stage. In addition to ericoid mycorrhiza, $P$. ericae forms mycorrhiza-like associations in liverwort rhizoids (Pressel et al., 2010; Kowal et al., 2018), and it has been found as an Antarctic moss endophyte (Zhang et al., 2013). However, no liverworts were visible among the moss at our site, and no association of P. ericae with Polytrichum rhizoids is known.

Supporting the hypothesis of different controls, bacteria and fungi showed distinct richness and biomass patterns along the succession. The proportion of fungi in the PLFA data, assumed to represent the living biomass (Zhang et al., 2019), increased already in the moss stage. Bacterial richness peaked in the heath and fungal richness in the bare sand, and neither correlated with ecosystem productivity or community maturity defined as soil OM or plant richness. In general, richness and diversity link to ecosystem functions through the complex interaction between diversity and ecosystem stability and productivity (Loreau and de Mazancourt, 2013). Plant richness peaks in the middle or late succession (Bonet and Pausas, 2004; Peyrat and Fichtner, 2011; Prach et al., 2014). For microbes, few general patterns of richness or diversity with primary succession have emerged. In very young soils, richness is often low and then increases and stabilizes or even decreases in later stages (Jackson, 2003; Nemergut et al., 2007; Fierer et al., 2010; Williams et al., 2013; Jiang et al., 2018). Primary succession gradients where both bacteria and fungi have been studied show conflicting patterns with each other but generally agree on different trajectories for bacterial and fungal richness (Brown and Jumpponen, 2014; Cutler, et al., 2014; Dini-Andreote, et al. 2014; DiniAndreote, et al. 2016; Jiang, et al. 2018). In our case, fungal richness remained rather stable under vegetation covered stages, while bacterial richness had a unimodal response. What can be concluded from above and the present study is that fungi and bacteria do not follow the same trajectories during succession and are not equally shaped by the same factors.

The low bacterial richness in the bare sand stage can be related to the oligotrophic conditions (i.e. low environmental resource availability); richness already increased with the scattered 
499

500

501

502

503

504

505

506

507

508

509

510

511

512

513

514

515

516

517

518

519

520

521

522

523

524

525

526

527

528

529

530

presence of the grass $D$. flexuosa. Pioneering plants can influence bulk soil when plants are of sufficient size (Tscherko et al., 2004; Edwards et al., 2006; Miniaci et al., 2007). The high fungal richness in the bare sand together with the low fungal biomass, however, is unpredicted by theories that species richness should increase with the increase in resources and environmental heterogeneity (Stein et al., 2014; Cline et al., 2018). Some of the fungal richness in bare soil may represent dormant fungi, spores or hostless biotrophic fungi (Jumpponen, 2003; Rime et al., 2015). On the other hand, our observation that the unclassified fungi can be grouped into class level clusters that occurred consistently in replicate samples and across the sandy successional stages also hints that the fungal community in bare sand may be in one way or other selected or specialized.

The high bacterial richness in the heath coincided with the highest fungal biomass and highest occurrence of $P$. ericae, presumably forming mycorrhizae with the dominant ericoid plant E. nigrum. We suppose that the high bacterial richness is promoted by resources and niches provided by fungal mycelium and Empetrum litter, despite its high phenolic content and proposed adverse properties on microbial activity (Wardle et al., 1998; Gallet et al., 1999). In the forest, where the highest microbial richness would be expected if richness correlated positively with $\mathrm{OM}$, plant species richness, and productivity, bacterial diversity was lower than in the heath, possibly due to the environmental filtering effect of the low $\mathrm{pH}$ in the forest soil (Tripathi et al., 2018). The varied responses of bacterial and fungal richness and diversity to primary succession highlight the need to cover successional gradients with different parent material, vegetation and soil chemistry to understand microbial community patterns along succession.

Effects of soil chemistry on microbial communities can override biotic factors such as plant richness (Chen et al., 2016; Jiang et al., 2018), and the role of vegetation is emphasized in successional gradients where soil chemistry does not change markedly (Knelman et al., 2012; Cutler et al., 2014). Soil chemistry, vegetation and microbes are strongly intertwined in succession, and the present gradient from bare sand to mountain birch forest represents the common pattern where organic matter increases and the soil acidifies with increasing plant cover (Odum, 1969; Merilä et al., 2010). However, the largest microbial community shifts did not align with the largest shifts in soil chemistry or vegetation. No measured soil 
531 chemistry variable changed in parallel with the large bacterial community shift between moss 532 and lichen stages. Both cryptogam stages showed indicator microbial groups associated with

533 low $\mathrm{OM}$ and low $\mathrm{pH}$. These results suggest that the microbial shift from moss to lichen stage 534 is due to unmeasured effects of the lichen crust formation. Such factors could be better long535 term moisture retention by the lichen crust than the sparse mosses in the moss stage, 536 microenvironments provided by lichen crumbs in the belowground soil (de los Ríos et al., 537 2011) or the different chemical composition and secondary metabolites of mosses versus 538 lichens.

\section{Conclusions}

541 This study on inland sand dunes illuminates bacterial and fungal succession in relation to vegetation and soil chemistry in a less studied Arctic soil ecosystem. Successional dynamics may not be linear nor deterministic, which makes the space-for-time substitution in mosaics

544 of repeated plant communities that are thought to represent chronosequences challenging

545 (Walker et al., 2010). In our case, the soil organic matter helps link vegetation development 546 in the lichen, heath and forest with time. However, the moss and grass stages are equally

547 devoid of soil organic matter. The microbial community composition in the grass stage

548 suggests that this stage is not well connected to the progressive successional pathway from 549 bare sand to mountain birch forest. Our results highlight the importance of considering not 550 only vascular plants but also cryptogams, i.e. mosses and lichens and particularly the 551 potential dune keystone species Polytrichum piliferum, when defining the plant-microbe 552 interactions in succession. Taken together, the results indicate that the belowground transition 553 towards the later stages starts before the establishment of vascular vegetation. This means 554 that the belowground succession may have a conditioning effect on the vascular plant succession in the early primary succession. This work complements evidence that bacterial and fungal richness are not necessarily related to soil ecosystem productivity or change in plant species richness (Waldrop et al., 2006; Porazinska et al., 2018; Delgado-Baquerizo and Eldridge, 2019). Soil chemistry and the effects of plants on microbial resources and niches seem to be important factors driving succession. However, the key transitions in soil chemistry, vegetation and microbial community did not align, suggesting additional drivers such as competition between microbial taxa. Bacterial and fungal indicators identified in this work, including novel unclassified diversity, can signpost ecosystem transitions towards 
563

564

565

566

567

568

569

570

571

572

573

574

575

576

577

578

579

580

581

582

583

584

585

586

587

588

vascular plant cover. Understanding the drivers of the shift from bare to vegetated stage is crucial for restoration of vegetation on cold-climate soils suffering from erosion and vegetation loss under changing environment.

\section{Acknowledgements}

We thank Helena Jauhiainen, Riitta Nissinen and Manoj Kumar for help with sampling and DNA extraction, Anita Mäki for assistance with sequencing, and Outi Manninen for the vegetation inventory. This work was funded by Maj and Tor Nessling Foundation and the Academy of Finland (project 287545 to MMK).

\section{Author contributions}

MMK conceived the research and led the field work, HJ and MM conducted PLFA analyses, HJ conducted DNA work, analyzed all the data and performed the statistical analyses, MT provided expertise and resources for Ion Torrent sequencing, HJ and MMK wrote the manuscript, and all authors commented on the manuscript.

\section{References}

Anderson MJ. 2001. A new method for non-parametric multivariate analysis of variance. Austral Ecology 26: 32-46.

Arróniz-Crespo M, Pérez-Ortega S, De los Ríos A, Green TA, Ochoa-Hueso R, Casermeiro MÁ, de la Cruz, María Teresa, Pintado A, Palacios D, Rozzi R. 2014.

Bryophyte-cyanobacteria associations during primary succession in recently deglaciated areas of Tierra del Fuego (Chile). PloS One 9: e96081.

Baker WL, Walford GM. 1995. Multiple stable states and models of riparian vegetation succession on the Animas River, Colorado. Annals of the Association of American Geographers 85: 320-338. 
589 Bardgett RD, Walker LR. 2004. Impact of coloniser plant species on the development of 590 decomposer microbial communities following deglaciation. Soil Biology and Biochemistry

591 36: $555-559$.

592 Bengtsson-Palme J, Ryberg M, Hartmann M, Branco S, Wang Z, Godhe A, Wit P,

593 Sánchez-García M, Ebersberger I, Sousa F. 2013. Improved software detection and

594 extraction of ITS1 and ITS2 from ribosomal ITS sequences of fungi and other eukaryotes for

595 analysis of environmental sequencing data. Methods in Ecology and Evolution 4: 914-919.

596 Blaalid R, Carlsen T, Kumar S, Halvorsen R, Ugland KI, Fontana G, Kauserud H.

597 2012. Changes in the root-associated fungal communities along a primary succession gradient

598 analysed by 454 pyrosequencing. Molecular Ecology 21: 1897-1908.

599 Bonet A, Pausas JG. 2004. Species richness and cover along a 60-year chronosequence in 600 old-fields of southeastern Spain. Plant Ecology 174: 257-270.

601 Bowden RD. 1991. Inputs, outputs, and accumulation of nitrogen in an early successional

602 moss (Polytrichum) ecosystem. Ecological Monographs 61: 207-223.

603 Brooker RW, Maestre FT, Callaway RM, Lortie CL, Cavieres LA, Kunstler G,

604 Liancourt P, Tielbörger K, Travis JM, Anthelme F. 2008. Facilitation in plant

605 communities: the past, the present, and the future. Journal of Ecology 96: 18-34.

606 Brown SP, Jumpponen A. 2014. Contrasting primary successional trajectories of fungi and

607 bacteria in retreating glacier soils. Molecular Ecology 23: 481-497.

608 Brown AM, Warton DI, Andrew NR, Binns M, Cassis G, Gibb H. 2014. The fourth-

609 corner solution - using predictive models to understand how species traits interact with the

610 environment. Methods in Ecology and Evolution 5: 344-352.

611 Chapin FS, Walker LR, Fastie CL, Sharman LC. 1994. Mechanisms of primary

612 succession following deglaciation at Glacier Bay, Alaska. Ecological Monographs 64: 149-

613175 
614 Chen Y, Ding J, Peng Y, Li F, Yang G, Liu L, Qin S, Fang K, Yang Y. 2016. Patterns and

615 drivers of soil microbial communities in Tibetan alpine and global terrestrial ecosystems.

616 Journal of Biogeography 43: 2027-2039.

617 Cline LC, Hobbie SE, Madritch MD, Buyarski CR, Tilman D, Cavender-Bares JM.

618 2018. Resource availability underlies the plant-fungal diversity relationship in a grassland

619 ecosystem. Ecology 99: 204-216.

620 Connell JH, Slatyer RO. 1977. Mechanisms of succession in natural communities and their

621 role in community stability and organization. The American Naturalist 111: 1119-1144.

622 Cornelissen JH, Lang SI, Soudzilovskaia NA, During HJ. 2007. Comparative cryptogam

623 ecology: a review of bryophyte and lichen traits that drive biogeochemistry. Annals of Botany

624 99: 987-1001.

625 Cutler NA, Chaput DL, van der Gast CJ. 2014. Long-term changes in soil microbial

626 communities during primary succession. Soil Biology and Biochemistry 69: 359-370.

627 De Cáceres M, Legendre P. 2009. Associations between species and groups of sites: indices 628 and statistical inference. Ecology 90: 3566-3574.

629 de los Ríos A, Raggio J, Pérez-Ortega S, Vivas M, Pintado A, Green TA, Ascaso C,

630 Sancho LG. 2011. Anatomical, morphological and ecophysiological strategies in Placopsis

631 pycnotheca (lichenized fungi, Ascomycota) allowing rapid colonization of recently

632 deglaciated soils. Flora-Morphology, Distribution, Functional Ecology of Plants 206: 857-

633864.

634 Delgado-Baquerizo M, Eldridge DJ. 2019. Cross-biome drivers of soil bacterial alpha 635 diversity on a worldwide scale. Ecosystems 22: 1220-1231.

636 DeLuca TH, Zackrisson O, Nilsson M, Sellstedt A. 2002. Quantifying nitrogen-fixation in

637 feather moss carpets of boreal forests. Nature 419: 917-920.

638 Dini-Andreote F, de Cássia Pereira e Silva, Michele, Triadó-Margarit X, Casamayor

639 EO, van Elsas JD, Salles JF. 2014. Dynamics of bacterial community succession in a salt 
640 marsh chronosequence: evidences for temporal niche partitioning. The ISME Journal 8:

641 1989-2001.

642 Dini-Andreote F, Pylro VS, Baldrian P, van Elsas JD, Salles JF. 2016. Ecological

643 succession reveals potential signatures of marine-terrestrial transition in salt marsh fungal

644 communities. The ISME Journal 10: 1984-1997.

645 Dini-Andreote F, Stegen JC, van Elsas JD, Salles JF. 2015. Disentangling mechanisms

646 that mediate the balance between stochastic and deterministic processes in microbial

647 succession. Proceedings of the National Academy of Sciences 112: E1326-E1332.

648 Duc L, Noll M, Meier BE, Bürgmann H, Zeyer J. 2009. High diversity of diazotrophs in 649 the forefield of a receding alpine glacier. Microbial Ecology 57: 179-190.

650 Edgar RC, Haas BJ, Clemente JC, Quince C, Knight R. 2011. UCHIME improves sensitivity and speed of chimera detection. Bioinformatics 27: 2194-2200.

652 Edwards I, Bürgmann H, Miniaci C, Zeyer J. 2006. Variation in microbial community 653 composition and culturability in the rhizosphere of Leucanthemopsis alpina (L.) Heywood 654 and adjacent bare soil along an alpine chronosequence. Microbial Ecology 52: 679-692.

655 Egler FE. 1954. Vegetation science concepts I. Initial floristic composition, a factor in old656 field vegetation development. Plant Ecology 4: 412-417.

657 Ellenberg H. 2009. Vegetation ecology of Central Europe. Cambridge: Cambridge 658 University Press.

659 Fierer N, Nemergut D, Knight R, Craine JM. 2010. Changes through time: integrating 660 microorganisms into the study of succession. Research in Microbiology 161 8: 635-642.

661 Francini G, Liiri M, Männistö M, Stark S, Kytöviita M. 2014. Response to reindeer 662 grazing removal depends on soil characteristics in low Arctic meadows. Applied Soil Ecology 663 76: $14-25$.

664 Gallet C, Nilsson M, Zackrisson O. 1999. Phenolic metabolites of ecological significance in 665 Empetrum hermaphroditum leaves and associated humus. Plant and Soil 210: 1-9. 
666 Gornall JL, Jónsdóttir IS, Woodin SJ, van der Wal R. 2007. Arctic mosses govern belowground environment and ecosystem processes. Oecologia 153: 931-941.

668 Gornall JL, Woodin SJ, Jónsdóttir IS, van der Wal R. 2011. Balancing positive and 669 negative plant interactions: how mosses structure vascular plant communities. Oecologia 670 166: 769-782.

671 Hodkinson ID, Coulson SJ, Webb NR. 2003. Community assembly along proglacial chronosequences in the high Arctic: vegetation and soil development in north-west Svalbard. Journal of Ecology 91: 651-663.

Hodkinson ID, Webb NR, Coulson SJ. 2002. Primary community assembly on land - the missing stages: why are the heterotrophic organisms always there first? Journal of Ecology 90: $569-577$.

Holland-Moritz H, Stuart J, Lewis LR, Miller S, Mack MC, McDaniel SF, Fierer N. 2018. Novel bacterial lineages associated with boreal moss species. Environmental Microbiology 20: 2625-2638. Stenlid J, Brandström-Durling M, Clemmensen KE. 2012. New primers to amplify the fungal ITS2 region-evaluation by 454-sequencing of artificial and natural communities. FEMS Microbiology Ecology 82: 666-677.

Jackson CR. 2003. Changes in community properties during microbial succession. Oikos 101: 444-448. 

patterns and driving forces for bacterial and fungal communities along a glacier forefield chronosequence. Soil Biology and Biochemistry 118: 207-216.

Jones GA, Henry GHR. 2003. Primary plant succession on recently deglaciated terrain in the Canadian High Arctic. Journal of Biogeography 30: 277-296.

698 Jumpponen A. 2003. Soil fungal community assembly in a primary successional glacier forefront ecosystem as inferred from rDNA sequence analyses. New Phytologist 158: 569578.

King C, King G. 2014. Description of Thermogemmatispora carboxidivorans sp. nov., a carbon-monoxide-oxidizing member of the class Ktedonobacteria isolated from a geothermally heated biofilm, and analysis of carbon monoxide oxidation by members of the class Ktedonobacteria. International Journal of Systematic and Evolutionary Microbiology 64: 1244-1251. colonizer plants during early primary succession in a glacier forefield. Soil Biology and Biochemistry 46: 172-180.

Kõljalg U, Nilsson RH, Abarenkov K, Tedersoo L, Taylor AF, Bahram M, Bates ST, Bruns TD, Bengtsson-Palme J, Callaghan TM. 2013. Towards a unified paradigm for sequence-based identification of fungi. Molecular Ecology 22: 5271-5277.

713 Koster EA. 1988. Ancient and modern cold-climate aeolian sand deposition: a review.

714 Journal of Quaternary Science 3: 69-83.

715 Kowal J, Pressel S, Duckett JG, Bidartondo MI, Field KJ. 2018. From rhizoids to roots?

716 Experimental evidence of mutualism between liverworts and ascomycete fungi. Annals of 717 Botany 121: 221-227.

718 Kozich JJ, Westcott SL, Baxter NT, Highlander SK, Schloss PD. 2013. Development of a

719 dual-index sequencing strategy and curation pipeline for analyzing amplicon sequence data 
on the MiSeq Illumina sequencing platform. Applied and Environmental Microbiology 79:

Kuske CR, Yeager CM, Johnson S, Ticknor LO, Belnap J. 2012. Response and resilience of soil biocrust bacterial communities to chronic physical disturbance in arid shrublands. The ISME Journal 6: 886-897.

Lichter J. 1998. Primary succession and forest development oncoastal Lake Michigan sand dunes. Ecological Monographs 68: 487-510. RLL. 2014. Much beyond Mantel: bringing Procrustes association metric to the plant and soil ecologist's toolbox. PLOS ONE 9: e101238.

Loreau M, de Mazancourt C. 2013. Biodiversity and ecosystem stability: a synthesis of underlying mechanisms. Ecology Letters 16: 106-115. organisms control microbial abundance, diversity, and physiology in different types of biological soil crusts. The ISME Journal 12: 1032-1046.

Mäki A, Rissanen AJ, Tiirola M. 2016. A practical method for barcoding and size-trimming PCR templates for amplicon sequencing. BioTechniques 60: 88-90.

Makoto K, Wilson SD. 2019. When and where does dispersal limitation matter in primary succession? Journal of Ecology 107: 559-565. contributions of stochastic and deterministic processes in community assembly over a successional gradient. Ecology 99, 148-157. comment on distance-based redundancy analysis. Ecology 82: 290-297. 
746

747

748

749

750

751

752

753

754

755

756

757

758

759

760

761

762

763

764

765

766

767

768

769

770

771

vegetation composition along a successional gradient in a boreal forest. Applied Soil Ecology 46: $259-267$.

Miniaci C, Bunge M, Duc L, Edwards I, Bürgmann H, Zeyer J. 2007. Effects of pioneering plants on microbial structures and functions in a glacier forefield. Biology and Fertility of Soils 44: 289-297.

Montgomery DR. 2007. Soil erosion and agricultural sustainability. Proceedings of the National Academy of Sciences 104: 13268-13272.

Navarro-Noya YE, Jiménez-Aguilar A, Valenzuela-Encinas C, Alcántara-Hernández RJ, Ruíz-Valdiviezo VM, Ponce-Mendoza A, Luna-Guido M, Marsch R, Dendooven L. 2014. Bacterial communities in soil under moss and lichen-moss crusts. Geomicrobiology Journal 31: 152-160.

Nemergut DR, Anderson SP, Cleveland CC, Martin AP, Miller AE, Seimon A, Schmidt SK. 2007. Microbial community succession in an unvegetated, recently deglaciated soil. Microbial Ecology 53: 110-122.

Odum EP. 1969. The strategy of ecosystem development. Science 164: 262-270.

Oksanen J, Blanchet FG, Friendly M, Kindt R, McGlinn D, Legendre P, Minchin PR, O'Hara RB, Simpson GL, Solymos P et al. 2017. vegan: Community Ecology Package. R package version 2.4-2. https://CRAN.R-project.org/package=vegan.

Olson JS. 1958. Rates of succession and soil changes on southern Lake Michigan sand dunes. Botanical Gazette 119: 125-170.

Ortiz-Álvarez R, Fierer N, de los Ríos A, Casamayor EO, Barberán A. 2018. Consistent changes in the taxonomic structure and functional attributes of bacterial communities during primary succession. The ISME Journal 12: 1658-1667.

Pennanen T, Strommer R, Markkola A, Fritze H. 2001. Microbial and plant community structure across a primary succession gradient. Scandinavian Journal of Forest Research 16: $37-43$. 
Peres-Neto PR, Jackson DA. 2001. How well do multivariate data sets match? The advantages of a Procrustean superimposition approach over the Mantel test. Oecologia 129:169-178.

Peyrat J, Fichtner A. 2011. Plant species diversity in dry coastal dunes of the southern Baltic coast. Community Ecology 12: 220-226.

Pirinen P, Simola H, Aalto J, Kaukoranta J, Karlsson P, Ruuhela R. 2012.

Climatological statistics of Finland 1981-2010. Finnish Meteorological Institute Reports 1: $1-96$.

Poosakkannu A, Nissinen R, Männistö M, Kytöviita M. 2017. Microbial community composition but not diversity changes along succession in arctic sand dunes. Environmental Microbiology 19: 698-709.

Porazinska DL, Farrer EC, Spasojevic MJ, Bueno de Mesquita, Clifton P, Sartwell SA, Smith JG, White CT, King AJ, Suding KN, Schmidt SK. 2018. Plant diversity and density predict belowground diversity and function in an early successional alpine ecosystem. Ecology 99: 1942-1952.

\section{Powell JR, Karunaratne S, Campbell CD, Yao H, Robinson L, Singh BK. 2015.}

Deterministic processes vary during community assembly for ecologically dissimilar taxa. Nature Communications 6: 8444.

Prach K, Řehounková K, Lencová K, Jírová A, Konvalinková P, Mudrák O, Študent V, Vaněček Z, Tichý L, Petřík P. 2014. Vegetation succession in restoration of disturbed sites in Central Europe: the direction of succession and species richness across 19 seres. Applied Vegetation Science 17: 193-200.

Pressel S, Bidartondo MI, Ligrone R, Duckett JG. 2010. Fungal symbioses in bryophytes: new insights in the twenty first century. Phytotaxa 9: 238-253.

Quast C, Pruesse E, Yilmaz P, Gerken J, Schweer T, Yarza P, Peplies J, Glockner FO. 2013. The SILVA ribosomal RNA gene database project: improved data processing and webbased tools. Nucleic Acids Research 41: D590-6.

RCoreTeam. 2018. R: A language and environment for statistical computing. Vienna, Austria: Foundation for Statistical Computing. https://www.R-project.org/ 
801 Read DJ. 1991. Mycorrhizas in ecosystems. Experientia 47: 376-391.

802 Rime T, Hartmann M, Brunner I, Widmer F, Zeyer J, Frey B. 2015. Vertical distribution

803 of the soil microbiota along a successional gradient in a glacier forefield. Molecular Ecology

804 24: 1091-1108.

805 Schloss PD, Westcott SL, Ryabin T, Hall JR, Hartmann M, Hollister EB, Lesniewski

806 RA, Oakley BB, Parks DH, Robinson CJ et al. 2009. Introducing mothur: open-source,

807 platform-independent, community-supported software for describing and comparing

808 microbial communities. Applied and Environmental Microbiology 75: 7537-7541.

809 Schmidt SK, Nemergut DR, Darcy JL, Lynch R. 2014. Do bacterial and fungal

810 communities assemble differently during primary succession? Molecular Ecology 23: 254-

811258.

812 Schmidt SK, Reed SC, Nemergut DR, Grandy AS, Cleveland CC, Weintraub MN, Hill

813 AW, Costello EK, Meyer AF, Neff JC et al. 2008. The earliest stages of ecosystem

814 succession in high-elevation (5000 metres above sea level), recently deglaciated soils.

815 Proceedings of the Royal Society B-Biological Sciences 275: 2793-2802.

816 Seppälä M. 1995. Deflation and redeposition of sand dunes in Finnish Lapland. Quaternary

817 Science Reviews 14: 799-809.

818 Smith SE, and Read DJ. 2008. Mycorrhizal symbiosis. London, UK: Academic Press.

819 Sparrius L, Sevink J, Kooijman A. 2012. Effects of nitrogen deposition on soil and

820 vegetation in primary succession stages in inland drift sands. Plant and Soil 353: 261-272.

821 Sparrius LB, Kooijman AM. 2013. Nitrogen deposition and soil carbon content affect

822 nitrogen mineralization during primary succession in acid inland drift sand vegetation. Plant and Soil 364: 219-228.

824 Stein A, Gerstner K, Kreft H. 2014. Environmental heterogeneity as a universal driver of

825 species richness across taxa, biomes and spatial scales. Ecology Letters 17: 866-880. 

L, Vasco-Palacios AM, Thu PQ, Suija A et al. 2014. Global diversity and geography of soil fungi. Science 346: 1256688. the balance between stochastic and deterministic assembly of bacteria. The ISME Journal 12: 1072-1083.

Tscherko D, Hammesfahr U, Marx M, Kandeler E. 2004. Shifts in rhizosphere microbial communities and enzyme activity of Poa alpina across an alpine chronosequence. Soil Biology and Biochemistry 36: 1685-1698.

Van der Wal R, Brooker R. 2004. Mosses mediate grazer impacts on grass abundance in arctic ecosystems. Functional Ecology 18: 77-86.

Vanwalleghem T, Gómez JA, Infante Amate J, González de Molina M, Vanderlinden K, management change on soil erosion and agricultural sustainability during the Anthropocene. Anthropocene 17: 13-29.

841 Vitousek PM. 1994. Potential nitrogen fixation during primary succession in Hawaii

842 Volcanoes National Park. Biotropica 26: 234-240. controls fungal diversity across a plant diversity gradient. Ecology Letters 9: 1127-1135. in studies of ecological succession and soil development. Journal of Ecology 98: 725-736. based analysis of multivariate abundance data. Methods in Ecology and Evolution 3: 471-474. allelopathy. Biological Reviews 73: 305-319.

851 Weber B, Büdel B, and Belnap J, eds. 2016. Biological soil crusts: An organizing principle in drylands. Ecological Studies 226, Springer. 
853 Williams MA, Jangid K, Shanmugam SG, Whitman WB. 2013. Bacterial communities in

854 soil mimic patterns of vegetative succession and ecosystem climax but are resilient to change

855 between seasons. Soil Biology and Biochemistry 57: 749-757.

856 Wilson JB, Gitay H, Roxburgh SH, King WM, Tangney RS. 1992. Egler's concept of

857 'initial floristic composition' in succession: Ecologists citing it don't agree what it means.

858 Oikos 64: 591-593.

859 Xie C, Lou H. 2009. Secondary metabolites in bryophytes: an ecological aspect. Chemistry

860 \& Biodiversity 6: 303-312.

861 Zhang T, Zhang Y, Liu H, Wei Y, Li H, Su J, Zhao L, Yu L. 2013. Diversity and cold

862 adaptation of culturable endophytic fungi from bryophytes in the Fildes Region, King George

863 Island, maritime Antarctica. FEMS Microbiology Letters 341: 52-61.

864 Zhang Y, Zheng N, Wang J, Yao H, Qiu Q, Chapman SJ. 2019. High turnover rate of free

865 phospholipids in soil confirms the classic hypothesis of PLFA methodology. Soil Biology and

866 Biochemistry 135: 323-330. 


\section{$867 \quad$ Figure legends}

868 Figure 1 (a) Six successional stages defined in deflation basins of an Arctic inland sand dune 869 area, (b) organic matter, (c) pH, (d) microbial biomass based on phospholipid fatty acids

870 (PLFAs) per soil organic matter (OM) content, (e) microbial biomass per gram soil dry 871 weight $(\mathrm{dw})$, (f) ratio of fungal to bacterial biomass based on PLFA, and ( $\mathrm{g}$ ) bacterial 16S 872 rRNA gene (upper row, darker colours) and fungal ITS amplicon (lower row, lighter colours)

873 OTU numbers in sand dune successional stages. Data are averages of four deflation basins 874 and three soil cores per basin. Ends of whiskers represent minimum and maximum values 875 excluding outliers, and outliers are shown as separate points. Different letters indicate 876 significant differences at $\mathrm{p}<0.05$.

878 Figure 2 Community structure of bacteria (a) as a non-metric multidimensional scaling 879 (NMDS) plot (stress=0.10) and (b) at phylum level (class level for Proteobacteria)

880 taxonomical classification based on 16S rRNA gene amplicon sequencing, and community structure of fungi (c) as an NMDS plot (stress=0.13) and (d) at class-level taxonomical

882 classification based on ITS2 region amplicon sequencing. Data points represent three soil 883 cores from four deflation basins per sand dune successional stage. Shapes of the symbols 884 represent separate deflation basins. In $\mathrm{b}$ and $\mathrm{d}$, data are averages of four deflation basins and 885 three soil cores per basin. For values of individual samples and the groups combined in 886 'other', see Fig. S4 and S7.

888 Figure 3 Average distances of successional stages from bare sand for bacterial, fungal, and 889 plant communities and for soil chemistry. Different letters indicate significant differences at $890 \mathrm{p}<0.05$. Ends of whiskers represent minimum and maximum values excluding outliers, and 891 outliers are shown as separate points.

893 Figure 4 Strength of correlation of vegetation with (a) bacterial community and (b) fungal 894 community determined as residuals of partial Procrustes analysis when variation due to soil 895 chemistry was partitioned out. Low values of the residuals indicate stronger correlation. 
896 Different letters indicate significant differences between the sand dune successional stages at $\mathrm{p}<0.05$.

898

899 Figure 5 Bacterial indicator OTUs for successional stages grouped at order level. Grey

900 shading shows where the successional stage changes, and each group is placed in the stage

901 where it was the most abundant (vertical successional stage labels; for., forest). Only groups

902 with total abundance of indicator OTUs $>0.05 \%$ are shown. The heatmap on the right shows

903 fourth corner coefficients (coeff.) describing the association of the indicator OTU groups

904 with environmental variables (env. variables). Positive coefficient indicates that the microbial

905 group occurred at high values of the environmental factor and negative coefficients indicate

906 occurrence at low values of the environmental factor. Ind. OTUs, number of indicator OTUs;

907 rel. abund., relative abundance; OM, organic matter.

908

909 Figure 6 Fungal indicator OTUs for successional stages grouped at class level. Grey shading

910 shows where successional stage changes, and each group is placed in the stage where it was

911 the most abundant (vertical successional stage labels: lich., lichen). A, Ascomycota; B,

912 Basidiomycota; R, Rozellomycota; Z, Zygomycota; cls, class; ord, order; Inc. sed., Incertae

913 sedis. Only groups with total abundance of indicator OTUs $>0.05 \%$ are shown. The heatmap

914 on the right shows fourth corner coefficients (coeff.) describing the association of the

915 indicator OTU groups with environmental variables (env. variables). Positive coefficient

916 indicates that the microbial group occurred at high values of the environmental factor and

917 negative coefficients indicate occurrence at low values of the environmental factor. Ind.

918 OTUs, number of indicator OTUs; rel. abund., relative abundance; OM, organic matter,

$919 \operatorname{minT}$, minimum soil temperature. 
a

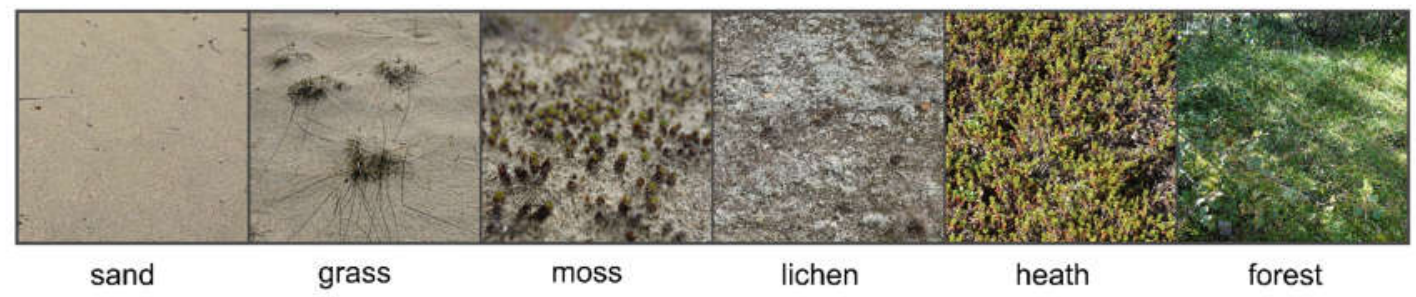

b
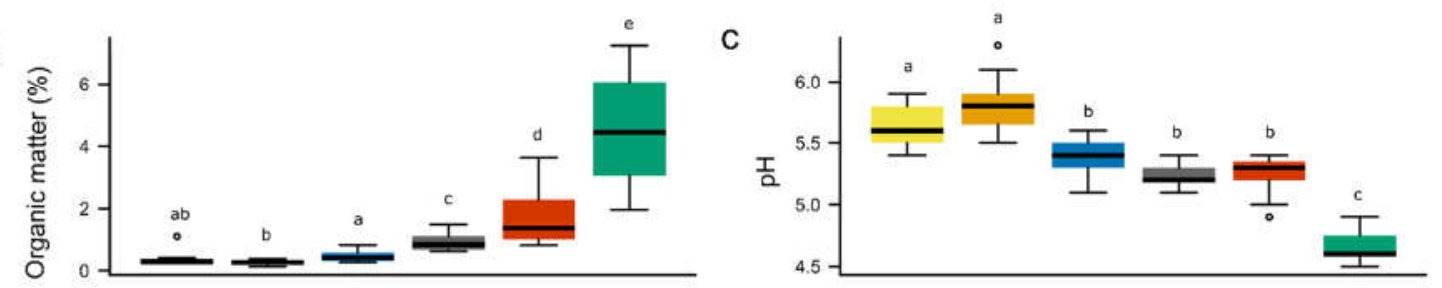

d
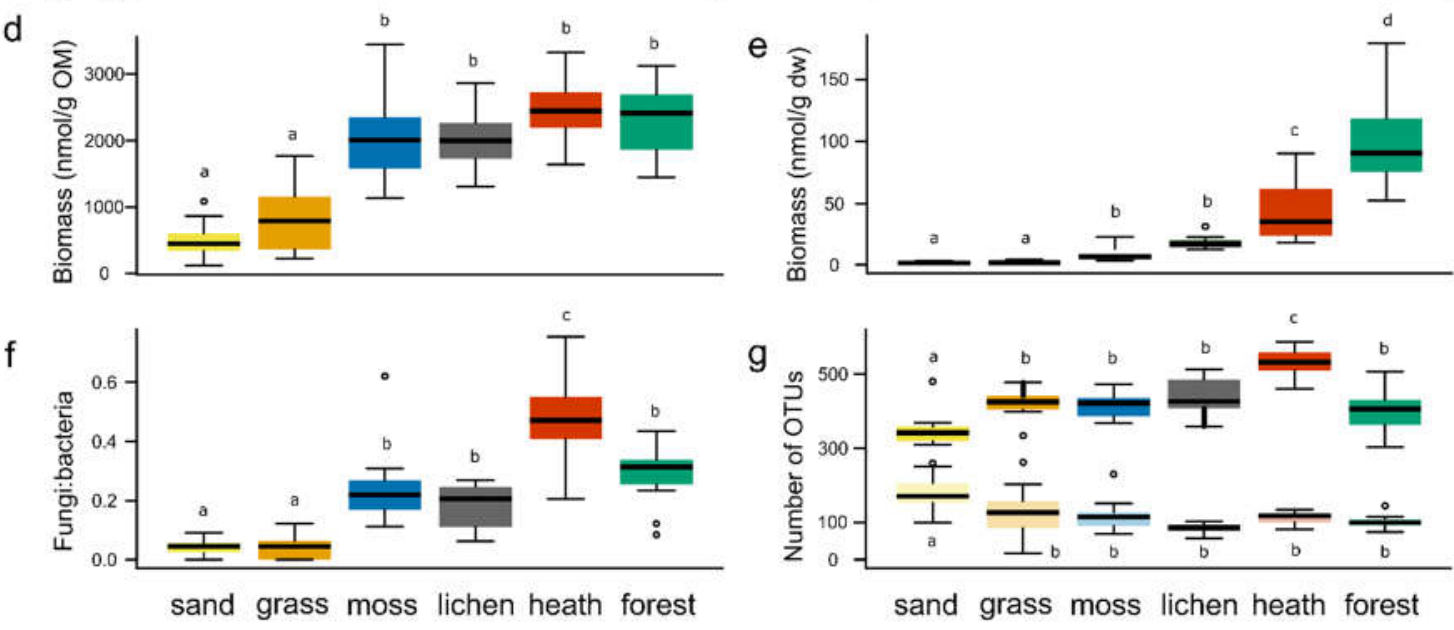

Figure 1 (a) Six successional stages defined in deflation basins of an Arctic inland sand dune area, (b) organic matter, (c) $\mathrm{pH}$, (d) microbial biomass based on phospholipid fatty acids (PLFAs) per soil organic matter (OM) content, (e) microbial biomass per gram soil dry weight (dw), (f) ratio of fungal to bacterial biomass based on PLFA, and (g) bacterial 16S rRNA gene (upper row, darker colours) and fungal ITS amplicon (lower row, lighter colours) OTU numbers in sand dune successional stages. Data are averages of four deflation basins and three soil cores per basin. Ends of whiskers represent minimum and maximum values excluding outliers, and outliers are shown as separate points. Different letters indicate significant differences at $\mathrm{p}<0.05$. 
a

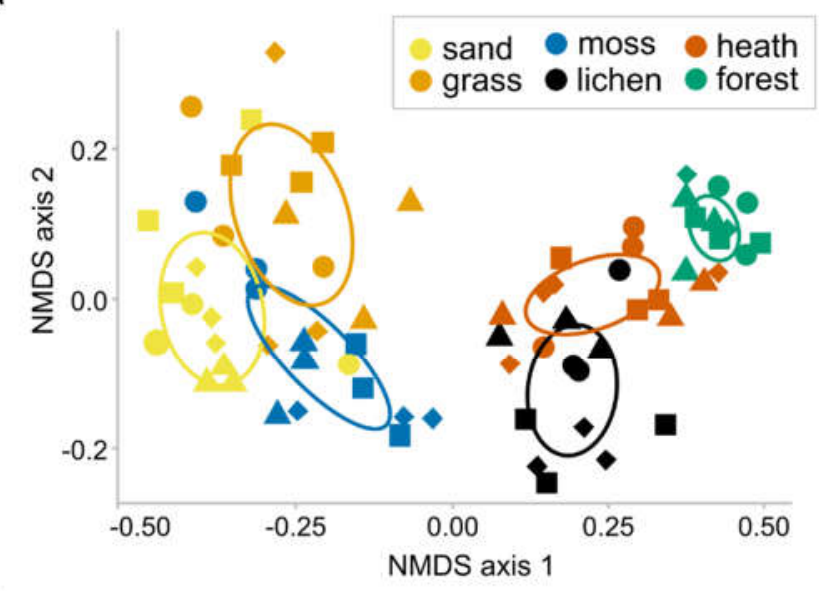

C



b



d

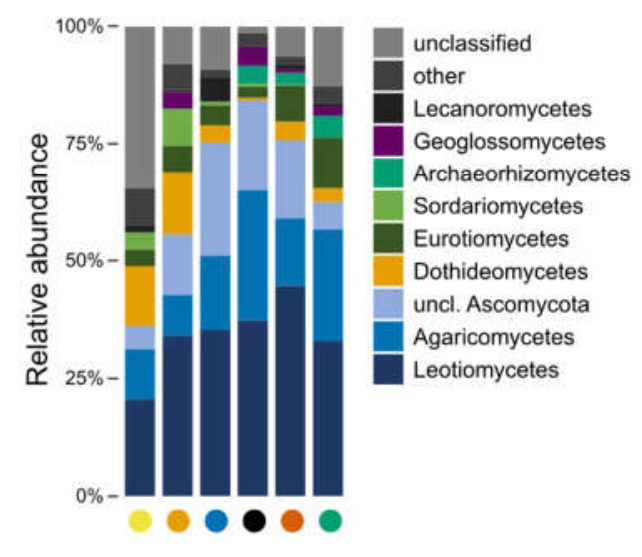

Figure 2 Community structure of bacteria (a) as a non-metric multidimensional scaling $(\mathrm{NMDS})$ plot (stress=0.10) and (b) at phylum level (class level for Proteobacteria) taxonomical classification based on 16S rRNA gene amplicon sequencing, and community structure of fungi (c) as an NMDS plot (stress=0.13) and (d) at class-level taxonomical classification based on ITS2 region amplicon sequencing. Data points represent three soil cores from four deflation basins per sand dune successional stage. Shapes of the symbols represent separate deflation basins. In $b$ and $d$, data are averages of four deflation basins and three soil cores per basin. For values of individual samples and the groups combined in 'other', see Fig. S4 and S7. 
a

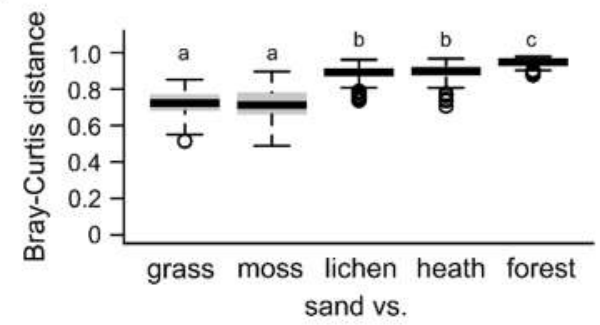

C

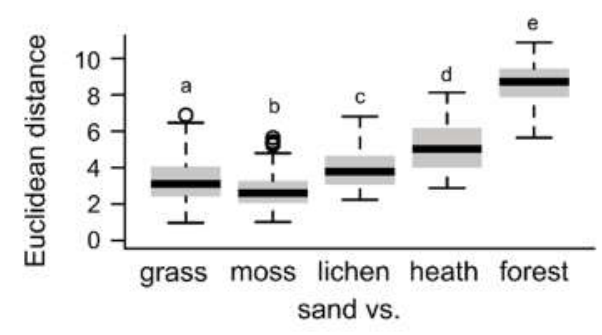

b



d

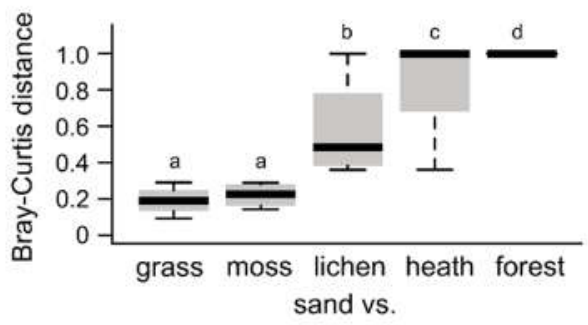

Figure 3 Average distances of successional stages from bare sand for bacterial, fungal, and plant communities and for soil chemistry. Different letters indicate significant differences at $\mathrm{p}<0.05$. Ends of whiskers represent minimum and maximum values excluding outliers, and outliers are shown as separate points. 
a

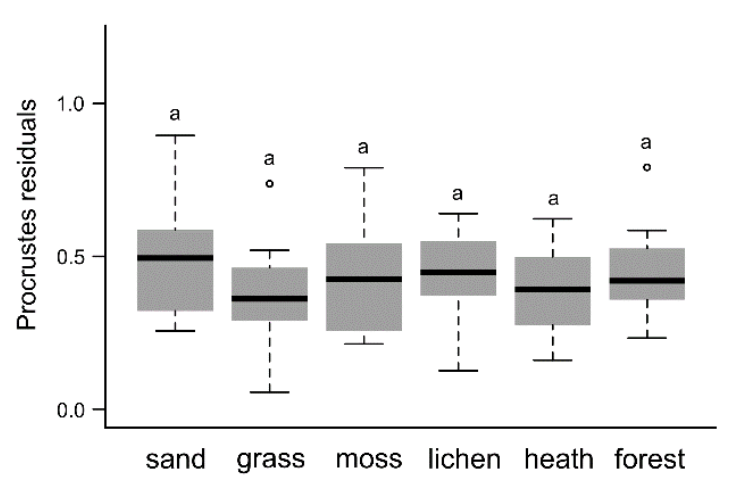

b

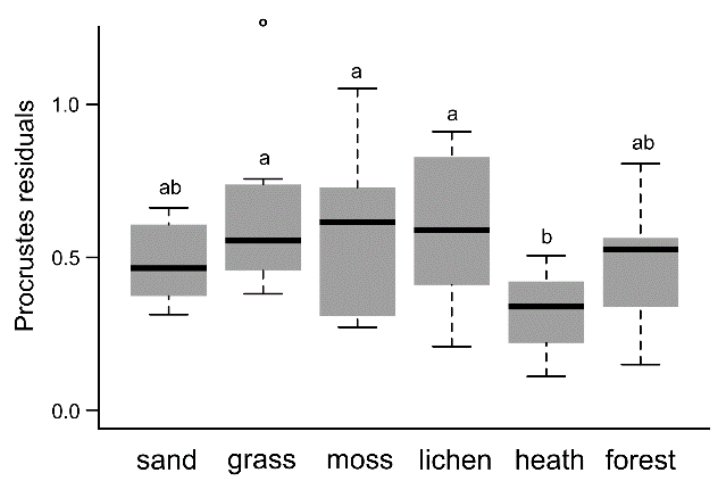

Figure 4 Strength of correlation of vegetation with (a) bacterial community and (b) fungal community determined as residuals of partial Procrustes analysis when variation due to soil chemistry was partitioned out. Low values of the residuals indicate stronger correlation. Different letters indicate significant differences between the sand dune successional stages at $\mathrm{p}<0.05$. 


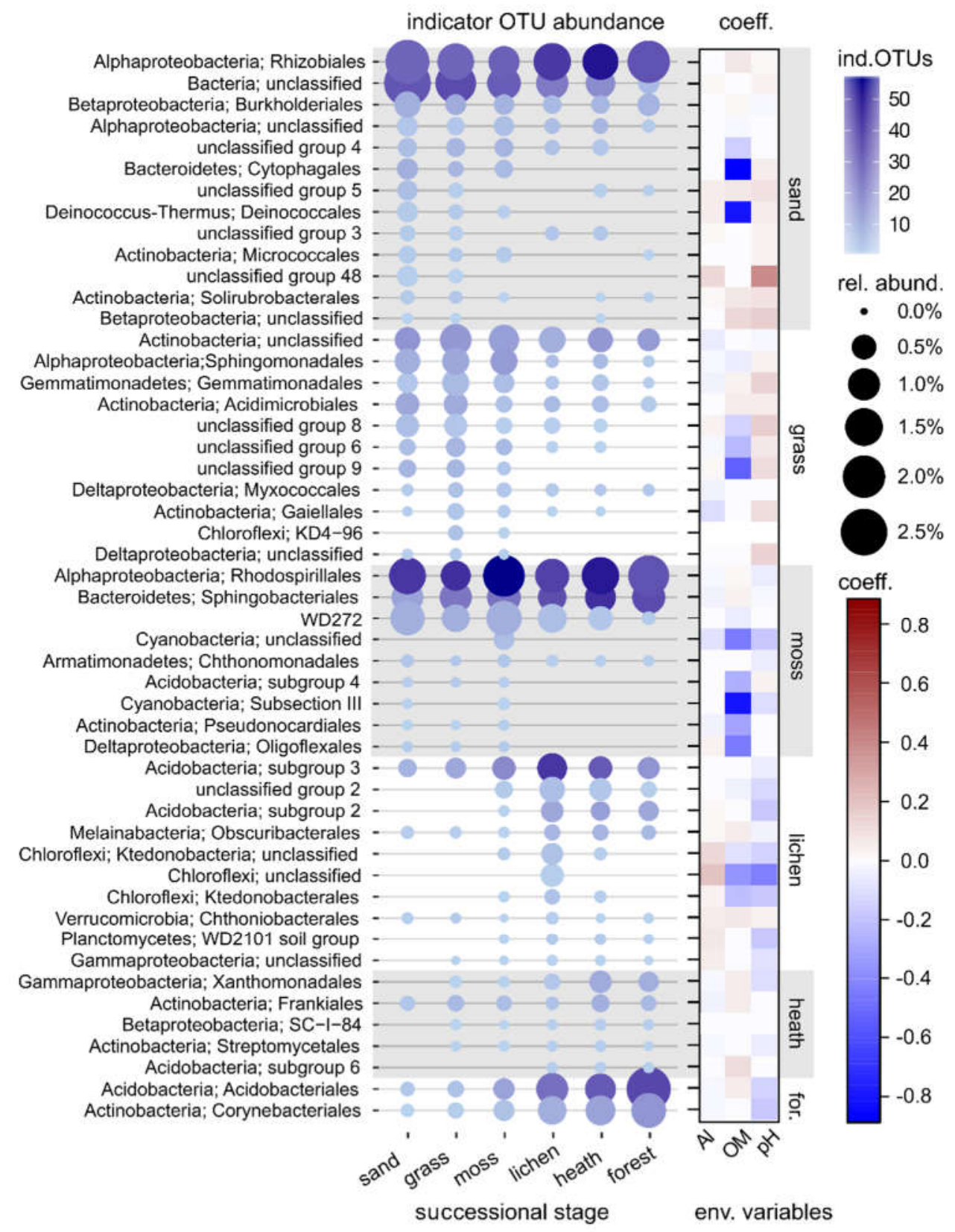

Figure 5 Bacterial indicator OTUs for successional stages grouped at order level. Grey shading shows where the successional stage changes, and each group is placed in the stage where it was the most abundant (vertical successional stage labels; for., forest). Only groups with total abundance of indicator OTUs $>0.05 \%$ are shown. The heatmap on the right shows fourth corner coefficients (coeff.) describing the association of the indicator OTU groups with environmental variables (env. variables). Positive coefficient indicates that the microbial group occurred at high values of the environmental factor and negative coefficients indicate occurrence at low values of the environmental factor. Ind. OTUs, number of indicator OTUs; rel. abund., relative abundance; OM, organic matter. 


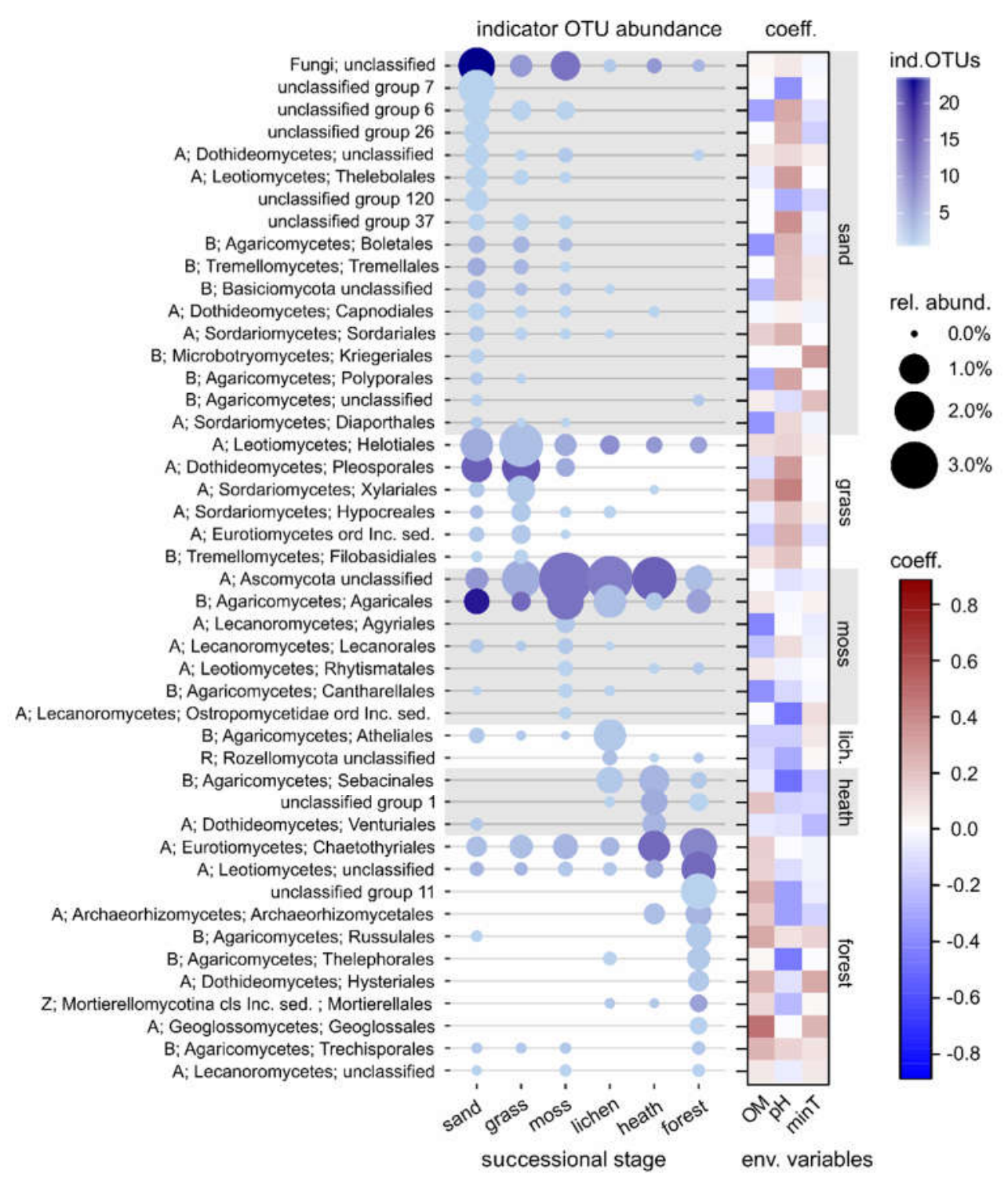

Figure 6 Fungal indicator OTUs for successional stages grouped at class level. Grey shading shows where successional stage changes, and each group is placed in the stage where it was the most abundant (vertical successional stage labels: lich., lichen). A, Ascomycota; B, Basidiomycota; R, Rozellomycota; Z, Zygomycota; cls, class; ord, order; Inc. sed., Incertae sedis. Only groups with total abundance of indicator OTUs $>0.05 \%$ are shown. The heatmap on the right shows fourth corner coefficients (coeff.) describing the association of the indicator OTU groups with environmental variables (env. variables). Positive coefficient indicates that the microbial group occurred at high values of the environmental factor and negative coefficients indicate occurrence at low values of the environmental factor. Ind. OTUs, number of indicator OTUs; rel. abund., relative abundance; OM, organic matter, minT, minimum soil temperature. 